\title{
МЕНТАЛЬНАЯ ОСНОВА ПРАВОВОЙ КУЛЬТУРЫ РОССИИ ${ }^{1}$
}

\section{THE MENTAL BASIS OF LEGAL CULTURE OF RUSSIA}

\section{Z. Kalandarishvili \\ D. Gezenko}

Summary: In the study, the authors discuss the problem associated with the mental basis of Russian legal culture. It acts as a kind of criterion in determining the quality side of the legal reality of people's lives. According to the authors of the article, historically established legal customs and traditions will always be part of the legal culture of citizens. They reflect the deep «layers» of morality, psychology, ideology and legal consciousness of a person.

Keywords: culture, legal culture, mental basis of legal culture, state, mentality, legal consciousness, spiritual values.

\author{
Каландаришвили Зураб Нодарович \\ К.ю.н., к.п.н., профессор, Санкт-Петербургский \\ Гуманитарный Университет Профсоюзов \\ zurab.kalandarishvili@yandex.ru \\ Гезенко Дарья Павловна \\ Старший преподаватель, Санкт-Петербургский \\ Гуманитарный Университет Профсоюзов \\ billy_92@mail.ru
}

Аннотация: В исследовании авторы рассуждают о проблеме, связанной с ментальной основой российской правовой культуры. Она выступает своеобразным критерием в определении качественной стороны правовой реальности жизни людей. По мнению авторов статьи, частью правовой культуры граждан всегда будут выступать исторически сложившиеся правовые обычаи и традиции. Они отражают глубинные «пласты» нравственности, психологии, идеологии и правового сознания человека.

Ключевые слова: культура, правовая культура, ментальная основа правовой культуры, государство, менталитет, правовое сознание, духовные ценности.

да исследования правовой культуры из узко-государственной трактовки в более широкое правовое поле, в котором осязаемы духовно-культурные особенности конкретно-исторической правовой действительности, или то, что можно обозначить как «правовой дух», сохраняющий «сквозные» правовые архетипы.

Ментальная основа правовой культуры несет в себе постоянство и устойчивость индивидуальных, групповых, массовых и общественных духовно-психологических структур российского правового сознания, выражает этногенетический код общества, национальный характер народа, образ его жизни, быта и культуры в сфере права. Это такая духовная подсистема, которая всем ходом умственно-интеллектуального, культурного и иного развития российского общества призвана отразить психологический генотип российского этноса, сохранить его и по возможности приумножить.

Таким образом, в менталитете, в том числе и правовом, заложены специфические способы восприятия и понимания этносом своего внутреннего мира, основанного на системе ценностей, обуславливающие все сферы жизнедеятельности людей.

Для ментальной основы правовой культуры России характерным является традиционализм, коллективизм, ярко выраженный антииндивидуализм, склонность чрезмерно идеализировать определенные проявления
Менталитет отражает глубокий пласт общественного сознания и является своего рода возможностью выхо- 
жизни. Вместе с тем присутствует стремление к правде, добру, равенству и милосердию. Специфический отпечаток на российскую ментальность накладывает религиозное и этическое многообразие России [1, с.34].

Традиционно духовной ценностью в России признавалась сплоченность, крепость семейных отношений, верность в дружбе, сотрудничество, чувство локтя. Соперничество, конкуренция, предательство, измена, эгоизм, индивидуализм всегда имели негативный смысл $[5$, c.120].

В этом смысле, Д.С. Лихачев, обращаясь к различным письменным источникам, справедливо замечает, что «не было ни одного литературного произведения, которое проповедовало бы раздробленность, обособление русских княжеств. Борьба за разъединение Руси не могла быть популярной [6, с.47].

Н.А. Бердяев говорил о противоречивости характера русского народа, но не пытался духовностью объяснить его нищету, а изменения в судьбе России к лучшему видел не в отказе от духовности, а в ее синтезе с характерными для запада ответственностью, дисциплинированностью и законопослушностью $[2$, с.7].

На содержание ментальной основы правовой культуры россиян в значительной мере повлияло и то, что люди в России веками видели несправедливость, неправду, творимую властью, предвзятый характер решений судей и т.п., что не могло не вызвать у граждан отрицательного отношения к законам государства и к правосудию. Но при этом забывалось, что проще осуждать того, кто нарушает закон, чем самому его исполнять. Иными словами, куда труднее развивать свое правовое сознание и правовую культуру, в которых идет схватка взаимоисключающих мыслей; перед каждым человеком постоянно стоит выбор - жить по совести и закону или «забыть» об их существовании. Вместе с тем современный российский менталитет в целом обладает голосом совести, национальной терпимости и гражданственности. В этом следует искать духовно-правовые основания государственно-юридической системы России. В частности, большую роль сегодня может сыграть патриотизм как один из важнейших «духовных нервов» России $[3$, c.116].

Ментальная основа правовой культуры как неотъемлемый фактор жизнедеятельности любого индивида и всего общества детерминируется многими (и не только правовыми) факторами - экономической, социальной, политической, духовной обстановкой, «миром повседневности». Вместе с тем, оно стремится сохранить свое, специфическое - содержащиеся в ней определенные установки и ценности, которые включают в себя некие общеобязательные, иногда формально-определенные образцы, модели повседневной жизнедеятельности, которые формируются не только в процессе «сиюминутных обстоятельств» осознания идеи законности, правопорядка, но имеют и более глубокие корни, более глубинные «пласты» общественного и индивидуального сознания. Особый духовный настрой, специфический способ восприятия и оценки действительности и находят свое отражение в понятии «менталитет» («ментальность»).

В связи со сказанным, проблема исследования ментальной основы правовой культуры является сегодня весьма актуальной. Многие аспекты восприятия человеком, обществом таких сторон и явлений жизни, как-то: понимание индивидом своего места в системе социального целого, степень удовлетворения этим, отношение к труду и собственности, богатству и бедности; отношение к свободе и ее толкованию; суждение о праве и обычае, справедливости и равенстве и т.п. - эти и другие стороны реального бытия во многом своими истоками уходят в особенности менталитета каждого общества, в том числе и нашего российского, которое по своей сути очень самобытно и специфично.

Каковы же перспективы эволюции ментальной основы правовой культуры России?

В Российской Федерации к настоящему времени еще отсутствует, в полном смысле этого слова, ясно сформулированный правовой комплекс, связанный с оценкой деятельности государства, его структуры, с оценкой жизни общества и конкретных людей. Сегодня идут поиски, продолжаются дискуссии на различных уровнях, высказывается масса предложений как теоретиков, так и практиков. Кое-где в какой-то мере с различным эффектом намечаются или проводятся в тех или иных областях науки эксперименты, но они, по большому счету, не в состоянии пока в полной мере решить проблемы правовых основ существования российской государственности. Сегодня в сознании людей накопилось много негативного за годы проводимых реформ во всех областях социально-экономической, политической, правовой и духовной сфер. Многие специалисты справедливо говорят о том, что для сегодняшней России самая сложная проблема - как построить относительно безболезненно гражданское общество и правовое государство. Главное и самое трудное сегодня состоит в формировании и поддержке в массовом масштабе реальных образцов правового поведения, прежде всего в среде молодых российских граждан, т.е. в среде будущего России. Реально предположить, что сегодня подавляющее большинство молодежи России не имеет надлежащего представления о правах человека, возможно, многие молодые люди даже не догадываются, что существуют такие права. И пока не произойдут радикальные изменения в государственно-правовой жизни, ни о каких правах человека как факторе именно массовой правовой культуры, го- 
ворить пока не приходится, так же, как и ее основных ценностей, свойственных менталитету в рамках данной культуры. В российском обществе права человека - это пока еще ценностный эталон, не более того, хотя и четко обозначенный, особенно после недавних внесений поправок, в Конституции РФ.

Российская Федерация - это уникальная форма государственно-правового устройства, нетипичная, «обособленная» от классических образцов. Отсюда возникает и настоятельная потребность бережного отношения к ее истории, традициям и правовому менталитету российского народа.

Прав бесспорно в этой связи А.С. Запесоцкий, утверждая, что «у России есть шанс преодолеть катастрофический тренд европейской цивилизации: оставаться в границах духовного пространства русской цивилизации, исторически оправданного и выстраданного народом, и не участвовать в проектах западного мира» [4, с.268].

В иерархии целей общества и государства, в его пра- вовой системе, в практике ее осуществления интересы человека должны стоять всегда на первом месте. И когда мы говорим, что человек - «цель, а не средство», то мы имеем в виду именно заботу государства об охране прав и свобод каждого человека и его человеческого достоинства. Основные человеческие ценности, как-то: свобода, человеческое достоинство, справедливость, сама человеческая жизнь и ряд других - должны выступать в правовом опосредовании или, как справедливо подчеркивал В. С. Нерсесянц, «должны являться формально-правовыми качествами, должны входить в понятие права и правовой культуры, быть возможны и выразимы в правовой форме» [7, с.165].

В этой связи ментальная основа правовой культуры выступает своеобразным критерием в определении качественной стороны правовой реальности жизни людей, т.к. всегда частью правовой культуры граждан будут выступать исторически сложившиеся правовые обычаи и традиции, отражающие глубинные «пласты» нравственности, психологии, идеологии и правового сознания человека.

\section{ЛИТЕРАТУРА}

1. Байниязов Р.С. Правосознание и правовой менталитет в России: введение в общую теорию. - Саратов: СГУ, 2001. - 296 с.

2. Бердяев Н.А. Судьба России. - М.: Мысль, 1990. - 640 с.

3. Гуревич С.С. Менталитет и культура современного общества. - М.: Издательский дом СПб, 2008. - С. 116 - 117.

4. Запесоцкий А.С. Становление глобальной культуры и конфликты цивилизаций. - СПб.: СПБГУП, 2018. - 605 с.

5. Иконникова С.Н. Русский национальный характер: грани ментальности // Диалог культур и цивилизаций в глобальном мире. VII Международные Лихачевские научные чтения. - СПб., 2007. - С. 119-121.

6. Лихачев Д.С. Избранные труды по рукописной мировой культуре. - СПб.: СПбГУП, 2006. - 540 с.

7. Нерсесянц В.С. Актуальные проблемы теории государства и права. - М.: Норма-Инфа, 2001. - 816 с.

( К Каландаришвили Зураб Нодарович (zurab.kalandarishvili@yandex.ru), Гезенко Дарья Павловна (billy_92@mail.ru). Журнал «Современная наука: актуальные проблемы теории и практики» 